\title{
Improved individual hand hygiene compliance with a multimodal hand hygiene intervention - the results of the PROHIBIT (Prevention of Hospital Infections By Intervention and Training) project
}

\author{
T Van Der Kooi ${ }^{1 *}$, H Boshuizen ${ }^{2}$, S de Greeff ${ }^{1}, H_{\text {Grundmann }}^{3}$, W Zingg ${ }^{4}$, the PROHIBIT study group ${ }^{1}$
}

From 3rd International Conference on Prevention and Infection Control (ICPIC 2015)

Geneva, Switzerland. 16-19 June 2015

\section{Introduction}

The PROHIBIT study aimed at inventorying and analysing national and local infection prevention activities in Europe and to test two interventions of proven efficacy in central venous catheter $(\mathrm{CVC})$ bloodstream infection (CRBSI) reduction: a multimodal $\mathrm{CVC}$ bundle and a multimodal hand hygiene $(\mathrm{HH})$ improvement strategy.

\section{Objectives}

Analyze the contribution of individual health care workers' (HCW) $\mathrm{HH}$ compliance to the overall increase in $\mathrm{HH}$.

\section{Methods}

Intensive Care Units of 14 hospitals in 11 European countries participated in this prospective stepped wedge cluster-randomized trial. HH was evaluated by direct observation conform the World Health Organization. Ten centres collected individual HH compliance data of HCW. Generalized linear mixed modelling was used, of $\mathrm{HH}$ compliance (\%) per observation session.

\section{Results}

In 9762 sessions 46,729 HH opportunities of $1874 \mathrm{HCWs}$ were collected in the 10 centres. Seven of the 10 centres (7980 sessions) were allocated to implement the HH campaign, alone or with the CVC strategy. Average baseline compliance in these centres was $43.1 \%$, which increased to $60.8 \%$ after the start of the intervention. The proportion of HCWs with $0 \%$ compliance decreased from $26 \%$ during baseline to $11 \%$ after the implementation of the $\mathrm{HH}$ campaign whereas the proportion complying $100 \%$ doubled

${ }^{1} \mathrm{Clb}$, Bilthoven, Netherlands

Full list of author information is available at the end of the article from $16 \%$ to $33 \%$. Many HCWs were observed in $<4$ sessions only (34.4\%) and not all were assessed during both periods. Individual changes in $\mathrm{HH}$ and the variance among HCWs were evaluated in HCWs assessed in both periods, with $\geq 4$ observed sessions (5406) as HCWs with $<4$ sessions inflate the variance. Of these $375 \mathrm{HCWs} 70.4 \%$ increased $\mathrm{HH}>10 \%, 11.5 \%$ remained constant $( \pm 10 \%)$ and $16.5 \%$ decreased $>10 \%$. The variance among HCWs within hospitals when comparing both periods decreased $(\mathrm{p}=0.36)$. This implies that the difference between relatively poor and good compliers remained comparable.

\section{Conclusion}

The multimodal $\mathrm{HH}$ campaign in our multicentre study resulted in the significant increase of the average $\mathrm{HH}$ compliance. The HH improvement was due to behaviour change of the individual HCWs.

\section{Disclosure of interest}

None declared.

\section{Authors' details}

${ }^{1} \mathrm{Cl}$ b, Bilthoven, Netherlands. ${ }^{2} \mathrm{SIM}, \mathrm{RIVM}$, Bilthoven, Netherlands. ${ }^{3}$ Med Microbiology, University Medical Center of Groningen, Groningen, Netherlands. ${ }^{4} \mathrm{ICP}$, University Hospitals of Geneva, Geneva, Switzerland.

Published: 16 June 2015

\section{doi:10.1186/2047-2994-4-S1-P147}

Cite this article as: Van Der Kooi et al:: Improved individual hand hygiene compliance with a multimodal hand hygiene intervention - the results of the PROHIBIT (Prevention of Hospital Infections By Intervention and Training) project. Antimicrobial Resistance and Infection Control 2015 4(Suppl 1):P147. 